\title{
Leucoplakia of the oral cavity, smoking and arylhydrocarbon-hydroxylase inducibility
}

\author{
†LARS ANDRÉASSON \\ M.D. \\ $\dagger \dagger$ ROLF KORSGAARD \\ M.D. \\ *ERIK TRELL \\ M.D.
}

**GUNNAR BJÖRLIN M.D.

*INGRID MATtIASSON M.D.

* LeNA TRELL M.D.

\author{
*Section of Preventive Medicine, **Departments of Oral Surgery and †Oto-Rhino-Laryngeology, \\ University of Lund, Malmö General Hospital, S 21401 Malmö; and ††Departments of Lung Medicine \\ and Tumour Cytogenetics, University of Lund, S 22185 Lund, Sweden
}

\begin{abstract}
Summary
In a consecutive series of 53 cases of oral leucoplakia, smoking history, oro-dental status and arylhydrocarbon-hydroxylase (AHH) inducibility were assessed. There was an increased association of leucoplakia with smoking, particularly in the male cases, but no remarkable findings as to dental status. Overall, there was a slightly higher frequency of cases with high AHH inducibility than expected from a normal control population. This difference was confined to the smokers, where there was a statistically highly significant over-representation of high AHH inducibility and under-representation of low AHH inducibility. The figures in the non-smoking patients were close to the expected.
\end{abstract}

\section{Introduction}

The familial clustering of certain malignancies, such as carcinoma of the breast and carcinomas of the large intestine, has been known for a number of years and genetic factors have been reported to be of aetiological significance (Penrose, Mackenzie and Karn, 1948; Woolf, 1958). Tokuhata (1964), demonstrated in lung cancer a synergistic interaction between familial and smoking factors. These epidemiological data became explicable in biological terms when Kellerman and associates presented their data on arylhydrocarbon-hydroxylase (AHH) inducibility (Kellerman, Luyten-Kellerman and Shaw, 1973 a; Kellerman, Shaw and Lutyen-Kellerman, 1973b). They observed a statistically highly significant over-representation of high and inter- mediate $\mathrm{AHH}$ inducibility in cultured lymphocytes not previously exposed to hydrocarbons in the patients with pulmonary carcinomas. All thesa patients were heavy smokers. The association be-0 tween high and intermediate AHH inducibility, exposure to polycyclic aromatic hydrocarbons(PAH) and the occurrence of pulmonary carcinomas was putatively explained by AHH-mediated activation of PAH to epoxides (Huberman et al., 1971, 1972; Huberman and Sachs, 1977; Buty, Thompson and Slaga, 1976) or epoxide metabolites (Booth and Sims, 1974; Daudel et al., 1975), initiating malignant cell transformation. In vitro experiments have given evidence of a preferential binding of the PAH epoxide products to the guanine sequences of DNA (Grunberger et al., 1974), and it has even been postulated that this DNA-alteration might represent a biochemical basis of carcinogenesis (Korsgaard, 1979).

Subsequent studies were inconsistent with or even contradictory to the original report. There were difficulties in confirming the postulated model of genetically determined AHH inducibility in man (Gurtoo, Bejoa and Minowada, 1975; Nebert and Atlas, 1977). More recently, however, several studies including twin studies have verified that AHH inducibility is under genetic control (Atlas, Vessel and Nebert, 1975; Paigen, Gurtoo and Minowada, 1977). In clinical material, the findings of Kellerman's group have been confirmed by some reports (Guirgis et al., 1976; Korsgaard et al., 1977). A clustering of smokers with spinocellular carcinoma 
of the larynx (Trell et al., 1976), oral carcinoma (Trell et al., 1978, 1981) and laryngeal precanceroses (Trell et al., 1980), into the high and intermediate AHH induction groups has also been demonstrated. The authors now report the findings of $\mathrm{AHH}$ inducibility in relation to smoking habits and oro-dental status in oral leucoplakia.

\section{Material and Methods \\ Study group}

All cases with a clinical diagnosis of oral leucoplakia $(n=102)$ diagnosed at the Department of Oral Surgery and confirmed by histopathological examination at the Department of Pathology, Malmö General Hospital between the years 1964-1978, were invited to a smoking interview and AHH assessment at the Department of Preventive Medicine, Malmö General Hospital, in 1978-1979; $57(56 \%)$ of the cases responded to the invitation; 4 were excluded because the histopathological examination revealed carcinoma in situ. The retrospective study thus finally comprised 53 cases. In one case, the $\mathrm{AHH}$ sample was lost. All cases showed typical microscopical changes with hyperplasia and dysplasia of the epithelial cells, occasional hyperkeratosis but only slight to moderate, unspecific inflammation. In 7 cases, more pronounced metaplastic changes, atypias and mitoses in the epithelial cells were noted. There were 29 men aged 22-74 years (mean 49) and 24 women aged 32-72 years (mean 52).

\section{Control group}

The control group consisted of 118 healthy employees of the University Hospital, Lund, and various research workers who voluntarily offered blood samples for assay of AHH inducibility. Forty-one were smokers, 19 with a daily consumption exceeding 20 cigarettes. None of the control group had malignant disease at the time of examination or had previously undergone treatment for malignant neoplasm.

\section{Enzyme assessment}

Samples of venous blood $(8-10 \mathrm{ml})$ were procured from each subject and kept overnight in heparinized tubes at $+4^{\circ} \mathrm{C}$. The blood was then diluted with Parker 199 medium and layered over a column of Lymphoprep ${ }^{\circledR}$. After 40 min centrifugation at $400 \mathrm{~g}$ at room temperature, a distinct white ring on top of the Lymphoprep ${ }^{\circledR}$ column contained the lymphocytes (Böyum, 1968; Thorsby and Bratlie, 1970). These were washed in Parker 199, suspended in the same nutrient medium, and the lymphocyte yield was calculated by the standard Trypan blue dye exclusion test. After resuspension in Parker 199 complemented with fetal bovine serum, glutamine and antibiotics, the lymphocytes were stimulated with phytohaemagglutinin and pokeweed mitogen, initiating blast transformation, a modification of the method described by Busbee, Shaw and Cantrell (1972).

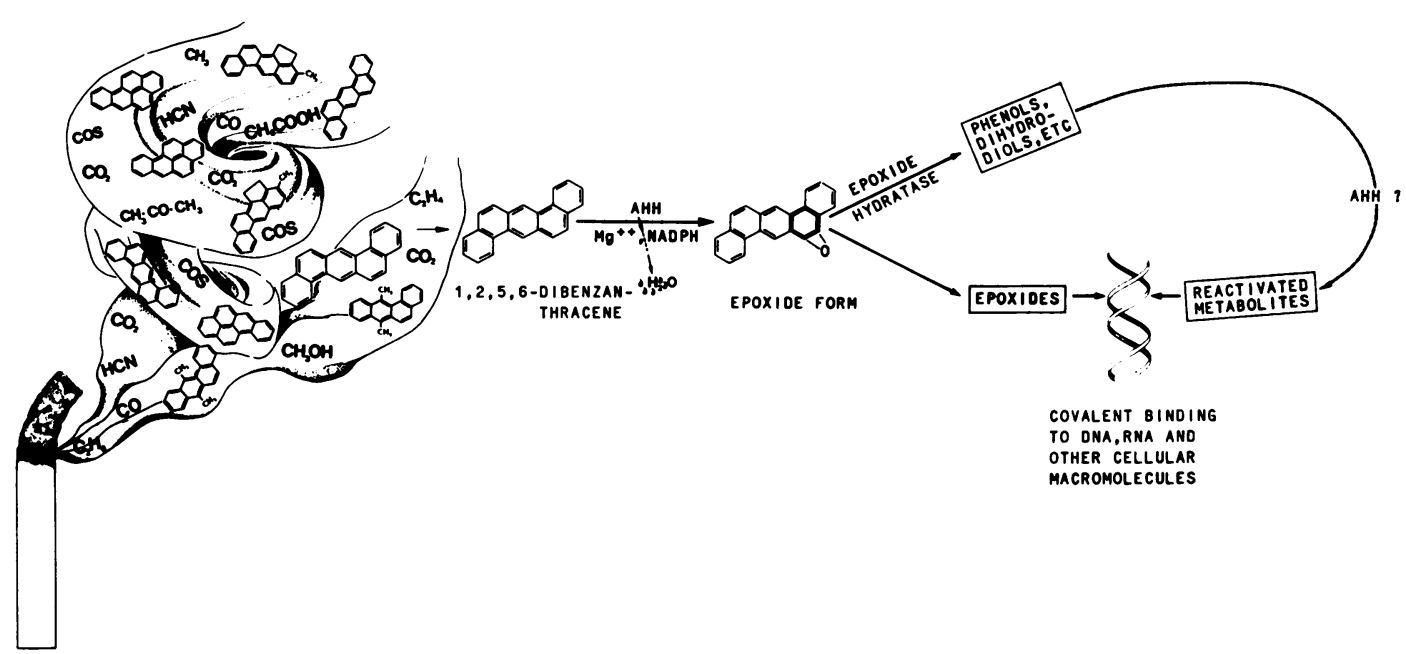

Fig. 1. Arylhydrocarbon-hydroxylase (AHH) activation of 1,2,5,6-dibenzanthracene and subsequent binding to cellullar macromolecules, such as DNA. The mixed-function oxygenase AHH is believed to activate polycyclic aromatic hydrocarbons (PAH) to reactive intermediates-ultimate carcinogens. This metabolism initially involves the microsomal oxidation of the double bonds and the formation of an epoxide. Epoxides are chemically labile, highly energetic and form covalent bonds with certain proteins, RNA and, most important, DNA. Also the diol-epoxides and the dihydro-diol-epoxides of unsubstituted PAH are of major importance and could be ultimately reactive forms of these carcinogenic compounds. 
At the end of $72 \mathrm{hr}$ in culture the lymphoblasts were tested for viability, divided into aliquots, and $1.5 \mathrm{mmol} 3$-methylcholantrene in acetone was added to the test samples and allowed to take effect for an additional $\mathbf{2 4} \mathrm{hr}$. Enzyme activity was then assayed according to a modified procedure of Nebert and Gelboin (1968) and Busbee et al. (1972), and the degree of inducibility determined spectro-photofluorometrically as fold induction in the presence and absence of 3-methylcholantrene.

\section{Clinical assessment}

At the time of the AHH analyses, all patients were asked to give a detailed account of the type, duration and consumption of tobacco up to the time of diagnosis of the oral leucoplakia.

All patient records were re-assessed with particular reference to oral hygiene, dental and denture status, location of oral leucoplakia and histological investigation of the leucoplakia lesions. Statistical significance was calculated according to the $\chi^{2}$ test with 2 degrees of freedom.

\section{Results}

Ninety per cent. of the male patients and $46 \%$ of the female were smokers. In general, the male smokers showed a higher tobacco consumption than the females.

There were no obvious associations between the histological appearance, size, shape or location of the lesions and age, sex or smoking habits of the patients.

Fourteen patients had dentures of some kind. These were functioning well and neither in the nonsmokers nor in the smokers did mechanical irritation by the denture appear to be the cause of the leucoplakias. The frequency of dentures in the material was not higher than expected in these age- and sex groups. In the control group the frequencies of high, intermediate and low AHH inducibility were $7 \cdot 6$, 41.5 and $50.9 \%$ respectively, which is in accordance with the data of Kellerman et al. (1973a) in a normal white U.S. population and in equilibrium with the Hardy-Weinberg law. There were no differences in the distribution in relation to smoking

TABLE 1. AHH inducibility distribution in the material. Expected frequencies were calculated from own reference material. Significance was calculated by the $\chi^{2}$-test. $\mathrm{NS}=$ not significant.

\begin{tabular}{lrrrrrr}
\hline \multirow{2}{*}{$\begin{array}{l}\text { AHH } \\
\text { inducibility }\end{array}$} & \multicolumn{2}{c}{ Total } & \multicolumn{2}{c}{ Smokers } & \multicolumn{2}{c}{$\begin{array}{c}\text { Non- } \\
\text { smokers }\end{array}$} \\
\hline Obs. & Exp. & Obs. & Exp. & Obs. & Exp. \\
High & 9 & 5 & 8 & 3 & 1 & 1 \\
Intermediate & 26 & 21 & 18 & 15 & 8 & 6 \\
Low & 17 & 27 & 11 & 19 & 6 & 8 \\
Significance & $P=0.01-0.005$ & $P=0.005-0.001$ & & NS \\
\hline
\end{tabular}

habits or sex. In the study group (Table 1) there were 9 cases with high $\mathrm{AHH}$ inducibility, 26 with intermediate and 17 with low inducibility. The frequencies expected from the control group were calculated as 5, 21 and 27 cases. When the material is divided into smokers and non-smokers, there is an obvious over-representation of individuals with high AHH inducibility among the smokers (8 against 3 expected cases) and also a slight under-representation of low values. These differences are significant $(P<0.005)$ while the figures for the non-smokers are close to the expected.

\section{Discussion}

There is ample evidence that carcinoma of the oral cavity is one group of malignant diseases associated with heavy smoking (Graham, 1977; Pindborg, 1980). The same association with smoking is documented also in oral leucoplakia, which is regarded as the most frequent precancerous state of the mouth (Bánóczy, 1977; Pindborg, 1980). In the discussion of the aetiology of oral malignancy, illfitting prostheses, bad crowns and fillings also receive considerable attention (Thumfart et al., 1978). In a previous series of oral carcinoma (Trell et al., 1981), no remarkable abnormalities in the orodental and denture status were found, while smoking was present in all the male cases and $50 \%$ of the female cases. In the present consecutive series of oral leucoplakia, the oro-dental and denture findings were also unremarkable, smoking was recorded in $90 \%$ of the male cases and about $50 \%$ of the female cases. In a recent population investigation in Malmö, $48.6 \%$ of 50 -year old males were found to be smokers (Janzon, et al., 1982).

The authors believe that these results add further support to the concept of AHH as an activator of proximate carcinogens, such as the PAH of tobacco smoke. However, it is hard to assess the spontaneous transformation rate of leucoplakia to carcinoma in the present material as this metabolic activation represents only one of several factors possibly involved in malignant transformation. Cessation of smoking might represent the most adequate prevention of malignant development in cases of oral leucoplakia where an association with smoking is apparent. The authors are continuously following their study group, but the present observation time is insufficient to draw definite conclusions on the further natural history in relation to factors like age, AHH inducibility, elimination or reduction of tobacco consumption and restorative oro-dental measures.

\section{Acknowledgment}

This study was supported by the Swedish Tobacco Company. 


\section{References}

Atlas, S.A., Vessel, E.S. \& Nebert, D.W. (1975) Aryl hydrocarbon hydroxylase induction in cultured human lymphocytes from monozygotic and dizygotic twins. Clinical Research, 23, 218.

BÁNóczy, J. (1977) Follow-up studies in oral leucoplakia Journal of Maxillofacial Surgery, 5, 69.

Воотн, J. \& Sims, P. (1974) 8,9-dihydro-8,9-dihydrobenz(a)antrhracene 10,11-oxide: A new type of polycyclic aromatic hydrocarbon metabolite. Federation of European Biochemical Societies. Letters, 47, 30.

BöyUM, A. (1968) Separation of leukocytes from blood and bone marrow with special reference to factors which influence and modify sedimentation properties of hematopoietic cells. Scandinavian Journal of Clinical and Laboratory Investigation, 21 (Suppl. 97), 1.

Busbee, D.L., Shaw, C.R. \& Cantrell, E.T. (1972) Aryl hydrocarbon hydroxylase induction in human leukocytes. Science, 178, 315.

Buty, S.G., Thompson, S. \& Slaga, T.J. (1976) The role of epidermal aryl hydrocarbon hydroxylase in the covalent binding of polycyclic hydrocarbon to DNA and its relationship to tumor initiation. Biochemical and Biophysical Research Communications, 70, 1102.

Daudel, P., Duquesne, M., Vigny, P., Grover, P.L. \& Sims, P. (1975) Fluorescent spectral evidence that benzo(a) pyrene-DNA products in mouse skin arise from diolepoxides. Federation of European Biochemical Societies. Letters, 57, 250.

Graham, S. (1977) Dentition, diet, tobacco and alcohol in the epidemiology of oral cancer. Journal of the National Cancer Institute, 59, 1611.

Grunberger, D., Blobstein, S.H., Harvey, R.G. \& WEINSTEIN, I.B. (1974) Binding of benz(a)pyrene (BP)-4,5epoxide and dimethylbenzanthracene (DBMA)-5,6-epoxide to nucleic acids in vitro. Abstracts from the XIth International Cancer Congress. Florence, 2, 48.

Guirgis, H.A., LYNCH, H.T., Mate, T., Harris, R.E., Wells, I., CAha, L., Anderson, J., Maloney, K. \& RANKIN, L. (1976) Aryl hydrocarbon hydroxylase activity in lymphocytes from lung cancer patients and normal controls. Oncology, 33, 105.

Gurtoo, H.L., BejBa, N. \& Minowada, J. (1975) Properties, inducibility and an improved method of analysis of aryl hydrocarbon hydroxylase in cultured human lymphocytes. Cancer Research, 35, 1235.

Huberman, E., Aspiras, L., Heidelberger, C., Grover, P.L. \& Sims, P. (1971) Mutagenicity to mammalian cells of epoxides and other derivatives of polycyclic hydrocarbons. Proceedings of the National Academy of Sciences of the United States of America, 68, 3195.

Huberman, E., Kuroki, T., Marquardt, H., Selkirk, J.K., Heidelberger, C., Grover, P.L. \& Sims, P. (1972) Transformation of hamster embryo cells by epoxides and other derivatives of polycyclic hydrocarbons. Cancer Research, 32, 1391.

Huberman, E. \& Sachs, L. (1977) DNA binding and its relationship to carcinogenesis by different polycyclic hydrocarbons. International Journal of Cancer, 19, 122.

Janzon, L., Lindell, S.-E., Trell, E. \& LaRme, P. (1982) Smoking habits and carboxyhemoglobin. Journal of Epidemiology and Community Health (in press).
Kellerman, G., Luyten-Kellerman, M. \& Shaw, C.R. (1973a) Genetic variation of aryl hydrocarbon hydroxylase in human lymphocytes. American Journal of Genetics, 25, 327.

Kellerman, G., Shaw, C.R. \& Luyten-Kellerman, M. (1973b) Aryl hydrocarbon hydroxylase inducibility and bronchogenic carcinoma. New England Journal of Medicine 289, 934.

KoRSGAARD, R. (1979) Chalones-a key to carcinogenesis? Journal of Medical Sciences, 7, 1.

Korsgaard, R., Stiksa, G., Simonsson, B.G. \& Trell, E. (1977) Smoking habits and aryl hydrocarbon hydroxylase inducibility in patients with malignant tumors of the respiratory tract. Scandinavian Journal of Respiratory Diseases, 99 (Suppl.), 50.

Nebert, D.W. \& Atlas, S.A. (1977) The Ah locus as a possible genetic marker for cancer. In: The Genetics of Human Cancer (Ed by Mulvihill, J. J., Miller, R. W. \& Fraumeni Jr, J. F.), p.301, Raven Press, New York.

Nebert, D.W. \& Gelboin, H.V. (1968) Substrate-inducible microsomal aryl hydroxylase in mammalian cell culture. I. Assay and properties of induced enzyme. Journal of Biological Chemistry, 243, 6242.

Paigen, B., Gurtoo, H.L. \& Minowada, J. (1977) Genetics of aryl hydrocarbon hydroxylase in the human population and its relationship to lung cancer. In: Polycyclic Hydrocarbon Carcinogenesis, (Ed by Tso, P. \& Gelboin, H. V.), Academic Press, New York.

Penrose, L.S., Mackenzie, H.J. \& Karn, M.N.A. (1948) Genetical study of human mammary cancer. British Journal of Cancer, 2, 168.

Pindborg, J.J. (1980) Oral Cancer and Precancer. John Wright \& Sons, Bristol.

Thorsby, E. \& Bratlie, A. (1970) A rapid method for preparation of pure lymphocyte suspensions. In: Histocompatibility Testing, (Ed by Terasaki, P. I.), Munksgaard, Copenhagen.

Thumfart, W., Weidenbecher, M., Wallek, G. \& Pesch, H.-J. (1978) Chronic mechanical trauma in the aetiology of oro-pharyngeal carcinoma. Journal of Maxillofacial Surgery, 6, 217.

TokuhatA, G.K. (1964) Familial factors in human lung cancer and smoking. American Journal of Public Health, $54,24$.

Trell, E., Korsgaard, R., Hood, B., Kitzing, P., Norden, G. \& Simonsson, B.G. (1976) Arylhydrocarbonhydroxylase inducibility and laryngeal carcinomas. Lancet, ii, 140.

Trell, E., KorsgaArd, R., Kitzing, P., Lundgren, K. \& Mattiasson, I. (1978) Arylhydrocarbonhydroxylase inducibility and carcinoma of oral cavity. Lancet, i, 109.

Trell, E., Korsgaard, R., Mattiasson, I., Kitzing, P. \& Trell, L. (1980) Smoking, arylhydrocarbonhydroxylase inducibility, and laryngeal precancerous lesions. IRCS Medical Science, 8, 339.

Trell, E., Buörlin, G., Andréasson, L., KorsgaArd, R. \& Mattiasson, I. (1981) Carcinoma of the oral cavity in relation to arylhydrocarbonhydroxylase inducibility, smoking and dental status. International Journal of Oral Surgery, 10, 93.

Woolf, C.M.A. (1958) A genetic study of carcinoma of the large intestine. American Journal of Human Genetics, $10,42$. 